\title{
A Study On The Effect Of Stress On Perception And Behavior Of Employees In A BPO Firm
}

\author{
Ms. Shishira Srinivasa \\ Part time Phd Scholar, BNMIT, Bangalore (Affiliated to VTU), India \\ Dr L.Vijayashree \\ Head-NewGen IEDC, ED Cell \& Professor -MBA DEPT, BNMIT, India
}

\begin{abstract}
As with other services, ITES Becoming one of the highly competitive service sectors in India. BPO organisations have been facing greater challenges since the beginning of this decade in terms of technological revolution, diversification of services and international operation. Stress is an important part that workers cannot prevent as processes, procedures; technology is being complicated with the use of advanced technology. Each employee cannot cope with such rapid workplace changes. This will help to create tension among employees. Through this research paper, an effort has been made to understand why the BPO workers are stressful and how employees deal with job stress. The maximum number of BPO staff is found to remain under stress. Most workers strive to find ways to alleviate tension. Steps are also suggested in the paper to overcome tension that affects their physical and mental health.
\end{abstract}

KEYWORDS: 'workplace stress, social life, health, satisfaction, conflict, stress management, employee stress, job stress, job perception, turnover intention, business process outsourcing, BPO, ITES'

Article Received: 10 August 2020, Revised: 25 October 2020, Accepted: 18 November 2020

\section{INTRODUCTION-}

The strain which contributes to the emotional and physical pressure arising from the conflict between our external environment and our environment. If you're a learner or working adult, it's hard to live without stress in our high pace environment. Given each individual's specific understanding of the conflict between the two forces, both positive and negative stress is present. Stress deliberately affects workers as much as the boss.(Khanka, p.319) Organizational India finally realises that a range of social potential is being drained by strain and explosion. (Shekhar Bajaj) Hazardous emotional and physical stress in the workplace

The emotional reaction arises when the job needs and the skills, resources or needs of the employee are poorly matched. These conditions may lead to poor performance or even injury. Various biological reactions, which can ultimately contribute to damaged health, are also associated with job distress.

Stress is the most common word and the least mentioned word in today's working world. The stress level depends on the characteristics of the sector, the worker's position and the job and tasks. Job stress is defined as a sequence of the work of psychological stressors created as a cumulative experience in an organisation at different levels due to working conditions. Employment stress is a significant determinant of environmental hypertension and is well studied in developed countries (Babu et al, 2013). Business Process
Among different segments in India, Industry outsourcing (BPO) in the sector of information technology enabled services (ITES). Cost advantages, adequate labor resources and infrastructure are the main reasons why global businesses are establishing BPOs in India. Even Indian businesses have started exporting their services to BPO organizations and the back-end procedure. Stress management, attrition and shift systems are some of the challenges in the Indian BPO industry. The present study has been conducted in this regard in order to know about stress management with regard to India in the BPO industry.

\section{Literature Review:}

Dayo Akintayo (2012) found that the working environment is significantly related to the "moral and also working environment of workers" and is significantly correlated with perceived productivity of workers. Dr. K. Chandrasekhar (2011) found that environmental factors are conducive to work and also found that factors that influence employee attitudes to work are interpersonal environmental control, shifting, emotional factors, job assignment, overtime duty, extended work. L.S.Kang, R.S. Sandhu (2011) stated in their article that stress is an individual's own state of mind when faced with a demanding situation or any constraint within an organisation that he/she feels harmful or threatening to him/herself. Stress emerges from various energy-saving conditions in the working environment. According to Pratibha Garg(2010) Job or occupational stress is the mismatch between 
individual skills and organisational requirements. Employees often experience stress due to work overload, expected work speed, etc.

Difficult schedules of work, conflict of roles, insecurity at work, bad interpersonal ties and stressful conditions of work. This stress can be seen in conflict, depression, headache, high blood pressure, alcohol and other conditions. In addition to losing revenue by paying medical bills, organisations often lose competitiveness.The Neelamegam and the SAsrafi (2010) said in their article that stress is a general term applied to the pressures felt in life. Strength at work is almost inevitable in many jobs. It has become a key buzzword and a legitimate concern of the time. According to N Kathirvel (2009) Stress is the reaction that people are taking due to excessive pressure or other types of demand on them. It happens when they do.

Fear that they can't cope with it. Stress is a demand for the adaptive capacity of the mind and the body. Kulkarni (2006) said in the Burnout article that a rapid change in modern working life is associated with increasing demands for new skills learning, the need to adopt new types of work, the pressure on higher productivity and quality of work, time pressure and hectic work are increasing stress among the workforce. He added that privatisation and globalisation have led to mergers, acquisitions and precarious employment. Anne Marie Berg et al.* in a 2006 study by the Norwegian police said that the prevalence of subjective health complaints was relatively high and was mainly related to job pressure and lack of support. Males showed more depressive symptoms than females. All frequency stress factors were positively associated with burnout and emotional exhaustion, except work injury. Sharma, Khera and Khandekar (2006) Computer Related Health Problems among Information Technology Professionals in Delhi The June 2010 Indian Journal of Community Medicine published more on visual stress and muscular skeletal symptoms, initially mild and temporary, and later on with increasing years assuming a more intense and permanent nature. It

It also found that computer-related morbidity had become an important and serious concern for occupational health. It suggested an immediate need for the authorities concerned to cooperate

And to enforce appropriate preventive measures. Barhem et al (2004) define stress as an extraordinary condition affecting individual human functions as a result of internal and external factors that are qualitatively different (with different types of stressors) and quantitatively different (with different types of stressors).
Number of stressors from individual performance, due to individual differences. Cobb (1975) is of the opinion that "responsibility burdens create serious stress between workers and managers." If the individual manager is unable to cope with increased responsibilities, there may be several physical and psychological disorders among them. Brook (1983) reported that qualitative changes in employment create an adjustment problem among employees. Interpersonal relations within

The department and the departments create qualitative difficulties within the organisation to a large extent.

\section{Workplace Stress:}

Conflict in the workplace is the negative physiological reaction that happens when the demands of the worker and his expertise, resources or needs are suited poorly. These conditions may lead to poor performance or even injury. Job stress is often associated with multiple biological responses, which can potentially contribute to health issues such as cardiovascular disease. Stress is a pervasive and expensive issue in today's workplace. Around a third of workers report chronic health issues. One quarter of workers consider their work as the number one stressor in their lives. Four employees think that the worker is more involved with the job than a decade ago. Evidence has shown that the main cause of turnover is tension in organisations.

\section{Symptoms of Stress:}

Absenteeism, escape from work obligations, staying early, leaving the office, job performance worsening, more error-prone work, cognitive impairment, etc., cribbing, exaggerating, argumentative, feeling annoyed, anxiety, health decline, more fatalities improper eating habits (over-eating or under-eating), excessive smoking and drinking, sleeplessness etc.

In the information technology (IT) and information technology enabled services (ITES) sector, Bhatt and Pathak (2010) have indicated that high attrition and absenteeism are observed. These variables contribute to the development of employee stress and have negative psychological consequences. The demographic variables also exacerbate the level of stress. Improving employee expectations in the outsourcing of business processes (BPO) sector can minimize problems such as burnout, attrition and stress (Combs et al, 2010).

Organizations need to concentrate on how to promote organizational engagement, increase job satisfaction, reduce work stress, and provide support to enable employee retention (Rekha and Kamalanabhan, 2010). Alternative job availability 
affects the dedication of employees to the organisation and ultimately contributes to turnover.

\section{Sources/Causes of Stress}

Pay/wage system suppression, strict rules and regulations, deterioration of communication, peer stress, uncertainty in goals/conflicts/goals, more centralised and structured organising culture, lower job opportunities, lack of decision-making skills in employers, undue control by managers over employees Single factors - For families, coworkers, supervisors and subordinates the employee has different standards. If such requirements are not understood or expressed, they lead to ambiguity/roles, which in turn leads to stress on employees. Other individual variables, such as impatience, aggression, rigidity, time pressure, etc., trigger stress among employees, are inherent personality characteristics. Similarly, family problems, personal financial concerns, abrupt changes in career all lead to stress. Work on variables - Stressful working environments, dangerous and unhealthy working conditions, instability, crowding Extra-organizational factors: in today's modern and technologically knowledgeable world stress has increased. Other non-organizational variables that cause stress include inflation, technological change, social responsibility and rapid changes in society.

\section{Stress Management:}

Collective negotiation is the time constraint. Life continues to find new ways to overwhelm and plague us with anxiety attacks, but it is hard to do more than just a stressful situation. Moreover, we appear to underestimate the stress sources and conditions they cause, regardless of our distress, mental effort or misguided attitudes. In these troubling moments, we sometimes overlook that stressors can be managed and treated equally because they are not readily observable.

\section{Strategies for Managing Stress}

Organizational stress management techniques promote more organisational contact with workers to ensure that ambiguity/conflict does not play a part. Effective communication may also alter workers' views. Managers should use better signs and signals that workers do not misunderstand; promote employee participation in decisionmaking. This reduces roles; provides workers with more flexibility, constructive and timely input and increased accountability; the organization's goals should be practical, motivating and precise. Feedback must be provided to employees about how far they are doing against these goals. It must promote decentralisation; a fair and fair allocation of benefits and pay structures; it must promote work rotation and employment enrichment;
Establish an environment for equal and safe work; provide an efficient recruitment and guidance process; Recognize workers for meeting and exceeding their objectives; Individual stress management techniques are staff who can list each day, prioritise the actions on the list and schedule the actions accordingly. Take daily breaks to rest when you are working. Employees can achieve their goals promptly by efficient time management and can meet job pressure to prevent stress; Do a tough job. Try to accomplish your goals, but don't hurt your family, health or peers. physical exercises. It contributes to the efficient circulation of your blood, keeps you fit, distracts you from working stresses and promotes a healthier lifestyle. Get regular sleep at night, get plenty of water, eat well. Promoting relaxation methods, including yoga, listening to music and meditation; workers should be optimistic about their jobs. They should avoid interactions with people with a negative approach; they should have emotional intelligence in the workplace. Self-confidence, self-confidence and self-control should take place in the workplace; workers should build social support. They should have close relationships with reliable peers who can listen to their problems and increase their trust. This social network allows workers to alleviate stress; employee therapy is an excellent strategy to overcome stress. Employees can understand their strengths and improve them through counselling; their weaknesses and how to remove them; and develop strategies to change their strengths.

Employees are also provided job counselling that helps to minimise their career ambiguities; find a healthy way to relieve tension, such as cracking, tennis, golf, etc. Help others by concentrating on them. This will relieve some tension.

\section{Targets-}

1. Study the causes of stress among workers.

2. Analyzing the degree of burden on workers.

3. Study the impact of depression on the health performance of staff.

4. To research the effects of tension on the efficiency of the company.

5. Study the impact of workload on the stress level of BPO workers.

6. Evaluate the value of intervention techniques at the organisational level to manage tension among BPO employees.

7. To research the role of stress in interpersonal relationships.

8. Research the success of the stress control programme organised by the BPO.

\section{Rationale:}


Like other utilities, BPO has become one of the most competitive industries in India. BPO organisations have been met with bigger problems since the beginning of this decade at the stage of technology revolution, significantly different and multinational BPO. This will lead to tension between employees. The researcher has chosen this subject as just a sample, while management of human resources is by far the most important resource of any organisation. At work, the HR of the organisations, especially the BPO, should be easy. Any stress/pressure affects their efficiency and the performance of the organisation directly. As competition increases daily, the tension of the employees also increases. Every employee needs a high and luxurious living standard.

Income, promotion, etc. They would also face a significant challenge in achieving work-related goals. This raises the workforce's tension. Each organisation is strongly competitive, which is why they want higher productivity with the proper use of resources, high sales and

High profit. High profit. The objective of the analysis is to define the main factors that create stress. The researcher will also study the cause of stress and suggest solutions to control stress among employees.

\section{Design of research:}

The study was of an explanatory nature. The size of the sample is 50. It was collected from employees of various BPOs located in Bangalore. Data was collected through a self-structured questionnaire. Books, websites, journals, etc. were used as a secondary data source. MS-Excel has been used to list and store data. Percentage Analysis method has been used to analyse and interpret results and to achieve research objectives.

\section{Findings and Conclusions:}

Most employees fear that lack of quality in their work puts them under stress. The maximum number of employees in BPO is found to remain under stress. $50 \%$ of employees feel that they are overloaded with work. 44 per cent of employees feel tense as a result of their failure to meet their work objectives. $38 \%$ of employees accepted that they would obey the order of their boss.

To sacrifice their important domestic function. This indicates fear and stress among employees. 32\% of employees feel stress due to their family-related problems. This means that they feel a higher level of stress compared to other employees. Half of the employees accepted that there was a conflict between the employees. This is a concern for top management. Only $48 \%$ of employees feel that the strategies used by BPO to manage employee stress are effective. Most employees try to find a solution to relieve them of stress. $50 \%$ of employees use YOGA or other means to relieve them of stress. In spite of stress, the majority of employees are balanced in their social life.

\section{Suggestions:}

BPO should take positive measures to relieve its workers from stress so that they are able to work with maximum productivity and efficiency, as most employees feel overwhelmed at work. BPO employees should be free not only from concern for the standard of their results but also from other fears. Personnel should be provided with guidance and advice, quality awareness programmes, and psychological support. The proposal for the fiveday working week should be implemented in BPO to give workers more time and social responsibilities to themselves and their families. BPO should schedule YOGA camp, counselling camp, facilities for entertainment, etc. The working environment should be clean and safe. There should be a fair division of labour in all divisions. For coworkers and in particular Boss, there should be a friendly atmosphere. Employees should seek performance excellence rather than fear.

\section{Limitations to the study:}

The timeframe for carrying out the research was short, as a result of which many facts were left unexplored. Lack of time and other resources, as it was not possible to carry out a survey at a large level. Thirty employees responded positively. The study is limited to the employees of the company. The selected branches of the nationalised BPO district of Bangalore and therefore the findings of the study cannot be extended to other areas. During the data collection, many employees were unwilling to fill out the questionnaire due to lack of time. Respondents had a feeling of wastage of time for them. Convenient sampling has been used in the study and has limitations of its own. The personal bias of the respondents may have crept in while answering a few questions. Results of this study It may not be generalised.

\section{Scope of further studies:}

The scope of the present study may be increased from the district level to the state level, national level as well as international level; the sample size may be increased; further demographic details may be added in future research and various other statistical tests may be used for comprehensive analysis and findings.

\section{REFERENCES}


1. Khanka, S.S. (2009). OrganizationalBehaviour, S.Chand,New Delhi, 319

2. Kathirvel N,(2009), The IUP Journal of ManagementResearch, Vol. VIII, No. 11, 28-44

3. Neelamegam R and Asrafi S,(2010), The IUP Journal ofManagement Research, Vol. IX,

No. 5, 57-69

4. Anne Marie Berg et al, ,stress burnout ${ }^{\mathrm{ee}}$. (2006), Journal ofOccupational Medicine and

Toxicology, 1:26 doi:10.1186/1745- 6673-1-26

8. Barhem, Belal, Samsinar, Md. Sidin., Abdullah, Iskandarand Alsagoff , Syed Kadir (2004),

9. New ModelforWorkplace Stress Patterns, Asian Academy ofManagement

Journal, Vol. 9, no.1, 53-77.

10. Karasek, R.A. (1979), „Job demands, job decision latitude, and mental strain: implications

for job redesign "Administrative Science Quarterly, 24, 285-307.

11. Karasek, R.A., K.P. Triantis and S.S. Chaudhry (1982),Co-worker and supervisor support

as moderators ofassociations between task.

12. Babu, G. R., Mahapatra, T., \& Detels, R. (2013). Job stress and hypertension in younger software professionals in India. Indian journal of occupational and environmental medicine, 17(3), 101-107.

13. Bhatt, S., \& Pathak, P. (2010). Occupational stress among IT/ITES professionals in leading metros in India: a case study. Asia Pacific Business Review, 6(3), 165-177.

14. Combs, G. M., Clapp-Smith, R., \& Nadkarni, S. (2010). Managing BPO service workers in India: Examining hope on performance outcomes. Human Resource Management: Published in Cooperation with the School of Business Administration, The University of Michigan and in alliance with the Society of Human Resources Management, 49(3), 457-476.

15. Cartwright, S., \& Cooper, C. L. (2002). ASSET: An organizational stress screening tool, The management guide. Manchester, UK: RCL Ltd

16. Khanka, S.S. (2009). OrganizationalBehaviour, S.Chand,New Delhi, 319
17. Chowdhury, N. and Menon, S. (1997), Beating Burnout,India Today, 9 June, 86 Dayo,

Garg P., (Sep 2010), Case Study, Vol 3, Punjab, $52-58$

18. Kathirvel N,(2009), The IUP Journal of ManagementResearch, Vol. VIII, No. 11, 28-44

19. Neelamegam R and Asrafi S,(2010), The IUP Journal ofManagement Research, Vol. IX,No. 5, 57-69 